\title{
Electrochemically Driven Stereoselective Approach to syn-1,2-Diol Derivatives from Vinylarenes and DMF
}

\author{
Da Sol Chung ${ }^{\dagger, \S}$, Steve H Park ${ }^{\dagger, \S}$, Sang-gi Lee*,† and Hyunwoo Kim*,† \\ Department of Chemistry and Nano Science, Ewha Womans University, 0376o Seoul, Korea
}

\begin{abstract}
We have developed an electrochemically driven strategy for the stereoselective synthesis of protected syn-1,2diols from vinylarenes with $N, N$-dimethylformamide (DMF). The newly developed system obviates the need for transition metal catalysts or external oxidizing agents, thus providing an operationally simple and efficient route to an array of protected syn-1,2-diols in a single step. This reaction proceeds via an electrooxidation of olefin, followed by a nucleophilic attack of DMF. Subsequent oxidation and nucleophilic capture of the generated carbocation with a trifluoroacetate ion is proposed, which gives rise predominantly to a syn-diastereoselectivity upon the second nucleophilic attack of DMF.
\end{abstract}

The dihydroxylation of alkenes is a fundamental and straightforward transformation for the preparation of 1,2diols, which is widely used in the preparation of key intermediates in fragrances, pharmaceuticals and functional materials. ${ }^{1}$ There are several classical methods that are capable of achieving this goal, including the Woodward-Prevost reaction ${ }^{2 a-c}$ and the epoxidation followed by ring-opening, ${ }^{2 \mathrm{~d}}$ in which both reactions proceed via cyclic intermediates that define the stereochemistry of the product (eq. 1 in Scheme $1 \mathrm{~A}$ ). A concerted syn-dihydroxylation mediated by $\mathrm{OsO}_{4}$ along with its asymmetric version, the Sharpless dihydroxylation, has also been recognized as the most widely used synthetic method for 1,2diols (eq. 2 in Scheme $1 \mathrm{~A}$ ). ${ }^{3}$ Despite these landmark achievements, the replacement of the use of an expensive and highly toxic osmium catalyst led to the dioxygenation of alkenes employing other metal-based catalysts which has successfully been developed in the presence of stoichiometric chemical oxidants such as $\mathrm{PhI}(\mathrm{OAc})_{2}$ or dioxygen (eq. 3 in Scheme $1 \mathrm{~A}$ ). 4 More recently, transitionmetal free approaches such as peroxide 5 or radical-mediated protocols ${ }^{6}$ have emerged as the alternative synthetic routes to 1,2-diols, although it is sometimes difficult to predict stereochemical outcome (eq. 4 in Scheme $1 \mathrm{~A}$ ).

Most of these precedent examples however still rely on the use of transition metals for the requisite redox process or otherwise require additional synthetic steps for the preparation of reaction mediators. In addition, an employment of a chemical oxidant system (e.g. hypervalent iodines) often leads to limited functional group compatibility. In this regard, we envisioned an electrochemical alkene oxidation as an ideal approach. Electrocatalytically driven organic synthesis allows to precisely select the redox potential for use, which circumvents selectivity and compatibility issue that often arise from its purely chemical counterparts. 7 Despite recent efforts in the development of electrochemical dialkoxylation, ${ }^{8}$ it is highly desirable to develop a conventional and stereoselective approach for 1,2-diol derivatives using feedstock chemicals.
Scheme 1. Synthetic Approaches to 1,2-Diols from Alkenes

(A) Previous approaches: alkene dioxygenation with chemical oxidants

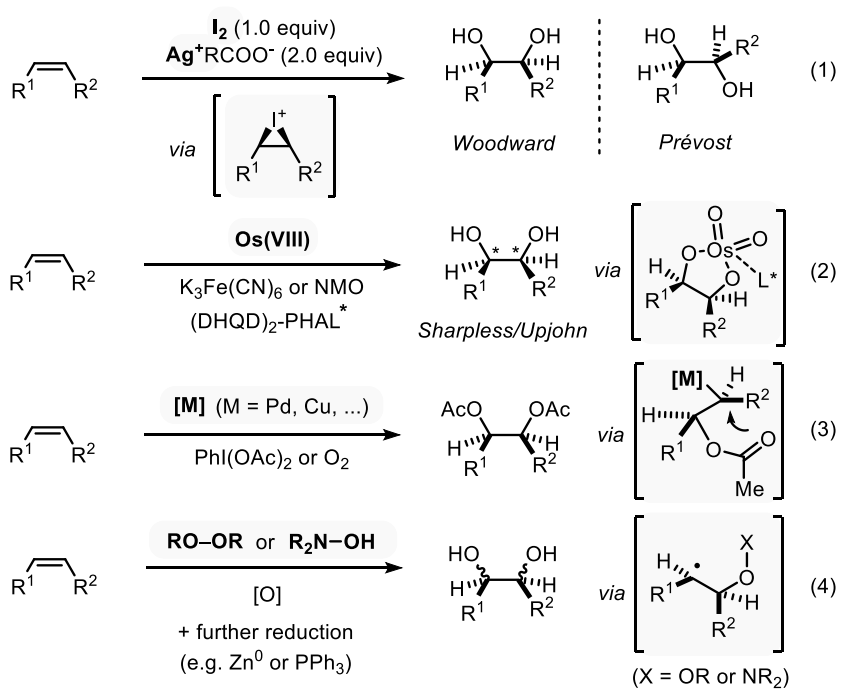

(B) This work: Electrochemical alkene syn-diformyloxylation promoted by TFA

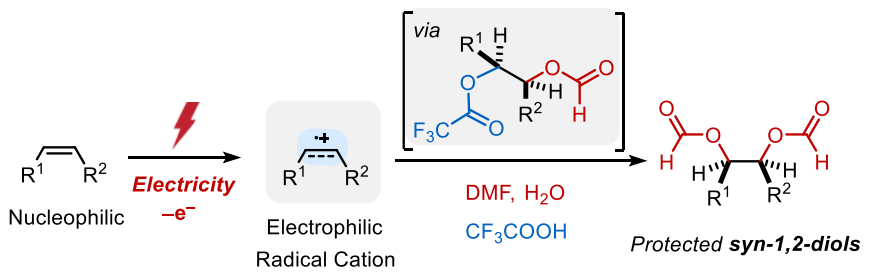

Herein, we report an electrochemical syn-diformyloxylation of vinylarenes using DMF as an oxygen source (Scheme 1B). This newly developed catalyst-free approach provides a straightforward and efficient route to a wide range of protected syn-1,2-diols in a single step. Electrochemical oxidation of alkenes to its radical cation enabled the direct addition of DMF, in which the formyloxy group derived from DMF can readily be converted into hydroxyl 
group. 9 Subsequent oxidation and a facile nucleophilic capture of the generated carbocation with a trifluoroacetate ion is proposed to grant high syn-diastereoselectivity upon second nucleophilic attack of DMF.

We set out to investigate our proposed olefin diformyloxylation by choosing 4-tert-butylstyrene (1) as the model substrate (Table 1). After optimization, we observed that the application of a constant cell voltage of $2.5 \mathrm{~V}$ (corresponding to an anodic potential of $1.3 \mathrm{~V}$ vs SCE) enabled the formation of a formyl protected diol $\mathbf{2}$ in 90\% yield (entry 1 ). The optimal conditions employed trifluoroacetic acid (TFA, 5.o equiv) and water (3.0 equiv) as additives, $\mathrm{TBABF}_{4}$ as the electrolyte, carbon felt and platinum plate as the anode and cathode respectively, in DMF. A control experiment without applied potential revealed that electric current is necessary for reactivity (entry 2 ). The reaction efficiency was significantly diminished when the reaction was conducted in the presence of molecular sieves, suggesting that stoichiometric amount of water is requisite for the reaction (entry 3). We found that the employment of acids weaker than TFA were detrimental to the reaction (entries 4-5). On the other hand, acids stronger than TFA were productive, albeit with slightly reduced efficiencies (entries 6-7). Switching the solvent from DMF into $\mathrm{CH}_{3} \mathrm{CN}$ significantly hampered the reactivity, even under high excess amount of DMF (entries 8-9). We have also found that the reactivity was not significantly affected when electrolysis was conducted under a constant current of $2 \mathrm{~mA}$ (entry 10). Notably, the reaction under $\mathrm{O}_{2}$ atmosphere was not beneficial for the desired transformation, showing a significant drop in reaction efficiency (entry 11). Similarly, the reactivity was found to be slightly diminished when the reaction was conducted open to air (entry 12).

\section{Table 1. Reaction Parameter Optimization ${ }^{a}$}

\begin{tabular}{|c|c|c|}
\hline 8 & $\begin{array}{c}\text { "standard conditions" } \\
\text { Undivided Cell } \\
\mathrm{CF}_{3} \mathrm{COOH} \text { ( } 5.0 \text { equiv), } \mathrm{H}_{2} \mathrm{O} \text { (3.0 equiv) }\end{array}$ & $\mathrm{H}$ \\
\hline $\begin{array}{c}\mathrm{R}=(4-t \mathrm{Bu}) \mathrm{C}_{6} \mathrm{H}_{4} \\
\mathbf{1}\end{array}$ & $\begin{array}{c}\mathrm{C}(+) / \mathrm{Pt}(-), U_{\text {cell }}=2.5 \mathrm{~V}\left(E_{a, i}=1.3 \mathrm{~V}\right) \\
\operatorname{TBABF}_{4}(0.13 \mathrm{M}), \mathrm{DMF}(3 \mathrm{~mL}), \mathrm{N}_{2} \\
22{ }^{\circ} \mathrm{C}, 12 \mathrm{~h}\end{array}$ & 2 \\
\hline Entry & Variation from "standard conditions" & Yield of $2(\%)$ \\
\hline 1 & none & $95(90)$ \\
\hline 2 & no applied voltage & $<5$ \\
\hline 3 & with $4 \AA$ molecular sieves & 33 \\
\hline 4 & $\mathrm{CH}_{3} \mathrm{COOH}$ instead of TFA & $<5$ \\
\hline 5 & $\mathrm{HCOOH}$ instead of TFA & 31 \\
\hline 6 & HOTf instead of TFA & 60 \\
\hline 7 & $\mathrm{HNTf}_{2}$ instead of TFA & 50 \\
\hline 8 & DMF (20 equiv) in $\mathrm{CH}_{3} \mathrm{CN}(0.05 \mathrm{M})$ & 25 \\
\hline 9 & DMF (10 equiv) in $\mathrm{CH}_{3} \mathrm{CN}(0.05 \mathrm{M})$ & 15 \\
\hline 10 & under constant current $\left(\mathrm{I}_{\text {cell }}=2.0 \mathrm{~mA}\right)$ & 75 \\
\hline 11 & under $\mathrm{O}_{2}$ atmophere (balloon, $1 \mathrm{~atm}$ ) & 45 \\
\hline 12 & under air atmosphere & 70 \\
\hline
\end{tabular}

${ }_{1}^{a}$ (o.2 mmol, 1.o equiv), $\mathrm{CF}_{3} \mathrm{COOH}$ (1.0 mmol, 5.o equiv), $\mathrm{H}_{2} \mathrm{O}$ (o.6 mmol, 3.o equiv), $\mathrm{TBABF}_{4}(\mathrm{o.1} \mathrm{M}), \mathrm{DMF}(3 \mathrm{~mL})$; cell voltage $\left(U_{\text {cell }}=\mathbf{2 . 5}\right.$ $\mathrm{V})$; yields determined by ${ }^{1} \mathrm{H}$ NMR (isolated yields in parenthesis).
To investigate the scope and functional group compatibility of the current diformyloxylation protocol, an array of terminal vinylarenes were initially examined (Table 2). Vinylarenes with different functional groups such as simple alkyls (2-4), acetoxy (5), ester (6) and halogen (7-9) groups at para-position were well tolerated. An ortho-substituted vinylarene (10), 2-vinylnaphthalene (11) and 1,1-disubstituted olefin (12) were also smoothly participated in the reaction without difficulties. Importantly, vinyl heterocycles derived from dibenzofuran (13) and carbazole (14) were also applicable to the current protocol, while pyridine, quinolone and thiophene derived vinyl heteroarenes were reluctant to participate in the reaction mainly due to the formation of polymeric side products. Interestingly, 1,2-diacetoxylation (15) product was obtained when $\mathrm{N}, \mathrm{N}$-dimethylacetamide (DMA) was employed as a solvent. Moreover, the reactivity toward biorelevant structures was examined to illustrate the installation of protected 1,2-diol group as a late-stage synthesis, furnishing estrone (16) and tyrosine (17) derivatives. It was also notable to see that a readily oxidizable electron rich alkene such as phenyl vinyl ether, ${ }^{10}$ could also be engaged in this reaction (18). To explore the stereoselectivity of the current procedure, we next set out to examine the scope of various internal alkenes. As summarized in Table 2, diformyloxylation of a wide range of internal alkenes granted access to products bearing vicinal stereogenic centers with good diastereocontrol. Dioxygenation of acyclic 1,2-disubstituted alkenes provided formyl-protected syn-diol products in good to excellent diastereomeric ratios (19-24, >7:1). Notably, substrates having labile groups on allylic positions underwent desired transformations without dissociation of the leaving groups (21-23). The cyclic alkenes such as dibenzosuberone and indene were viable substrates as well, albeit in somewhat diminished diastereoselectivity $(\mathbf{2 5}-\mathbf{2 6},>4$ :1, diastereomeric ratios). Interestingly, the reaction was found to be highly chemoselective towards a more readily oxidizable, electronically rich alkene when a substrate bearing multiple alkenes was tested. For example, cinnamyl cinnamate gave a monodioxygenated product $\mathbf{2 7}$ with high chemo- and diasteroselectivity. Trisubstituted alkenes were also reacted efficiently to afford the corresponding products in good diasteroselectivity (28-29). However, tetrasubstituted or unactivated alkenes derived from simple hydrocarbons were found to be recalcitrant to the current dioxygenation method (see Scheme $\mathrm{S}_{1}$ in Supplementary Information (SI) for unsuccessful substrates). The electrochemical diformyloxylation tested positive in the radical clock experiment with cycloproyl-substituted alkene 30, implying the intermediacy of a benzylic radical during the reaction. 
Table 2 Substrate Scope of Electrochemically Driven Olefin Dioxygenation ${ }^{\mathrm{a}}$
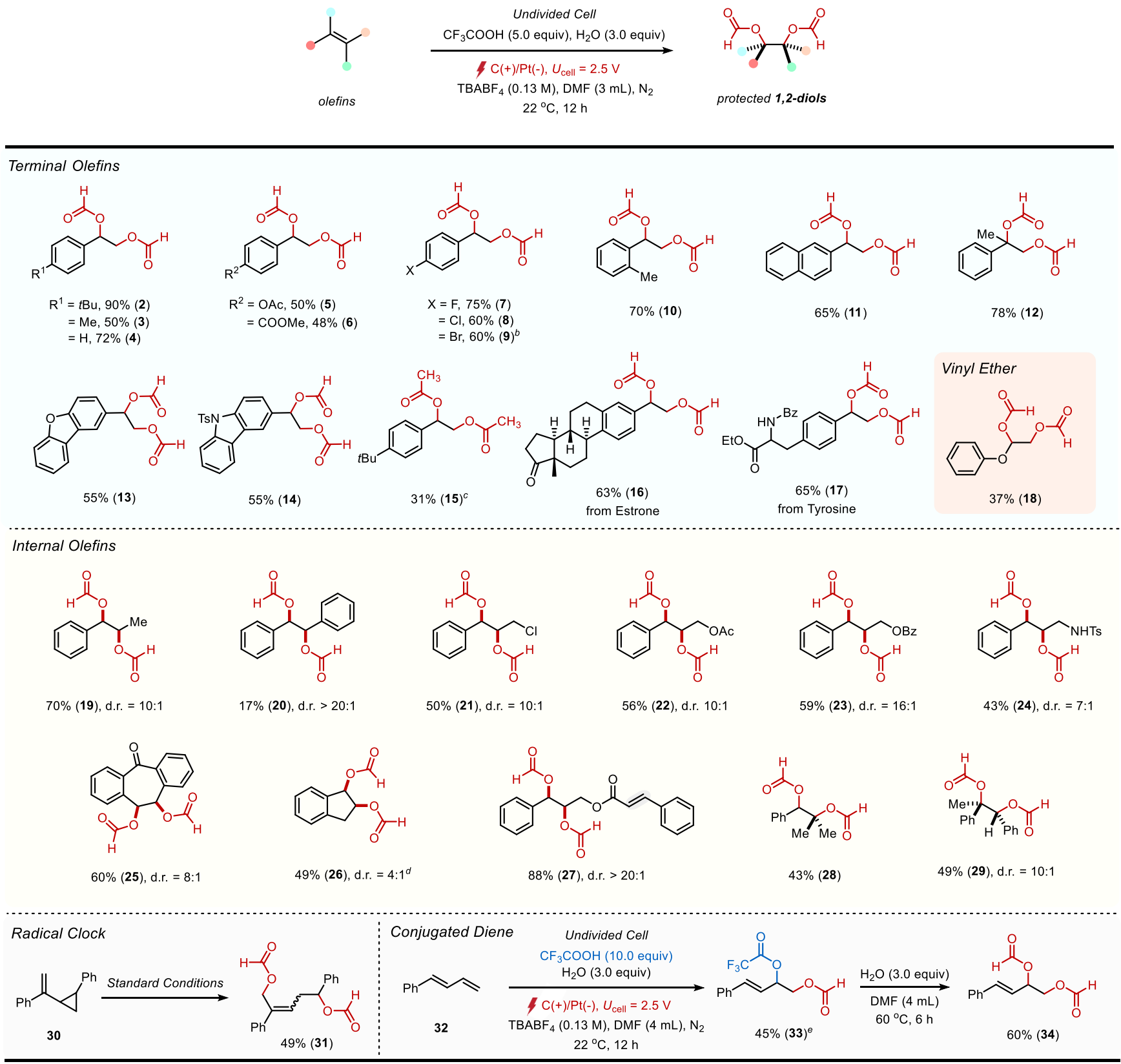

${ }^{a}$ Isolated yields are reported. Optimal conditions from Table 1 used. Diastereoselectivity was determined by ${ }^{1} \mathrm{H}$ NMR spectra of crude reaction mixture. ${ }^{b}$ Yield determined by ${ }^{1} \mathrm{H}$ NMR using 1,2-dimethoxyethane as an internal standard. ${ }^{c} N, N$-Dimethylacetamide (DMA) was used as a solvent. ${ }^{d} 10$ equiv of TFA was used. ${ }^{e} 5 \%$ of 33 was also obtained along with 32.

We have also found that the reaction took place selectively at the terminal position when 1,3-diene was employed as a substrate (32). Different from conventional vinylarene substrates, however, the dioxygenation product 33 possessing a trifluoroacetoxy group at 3-position was obtained as the major product $(45 \%)$ along with $5 \%$ of the desired product $(34)$. This observation led us to further investigate the possible intermediacy of our reaction. As hypothesized, we were able to observe the formation of desired diformyloxylation product 34 upon treatment of $\mathbf{3 3}$ with DMF in the presence of water.
The uncommon diastereoselectivity trend observed in this catalyst-free approach piqued our interest in elucidating its mechanism. The reaction under deuterated DMF- $d_{7}$ solvent revealed that the formyl groups in the product originate from DMF, as we envisioned at the outset (Figure $1 \mathrm{~A}$ ). In contrast, we found that the reaction with deuterated formic acid did not result in incorporation of deuterium on both formyl groups (Figure $1 \mathrm{~B}$ ). These findings suggested that the engagement of formic acid with the olefin radical cation is less conceivable, in which the formic acid is initially generated by hydrolysis of DMF in the presence of strong acid. ${ }^{a, 11}$ Notably, the stereo- 
outcome of this reaction was dependent on the alkenylic geometry of the starting materials, with the major isomers irrespectively arising from syn-diformyloxylation. For example, trans- and cis- $\beta$-methylstyrene (trans- and cis-35) both gave corresponding syn-diformyloxylation products with 10:1 and 3:1 of diastereomeric ratios respectively (Figure ${ }_{1} C$ ). We note that this retention of diastereoselectivity upon choice of the stereoisomeric starting materials is unusual compared to previous examples that employ different alkene oxidation strategies. ${ }^{12}$
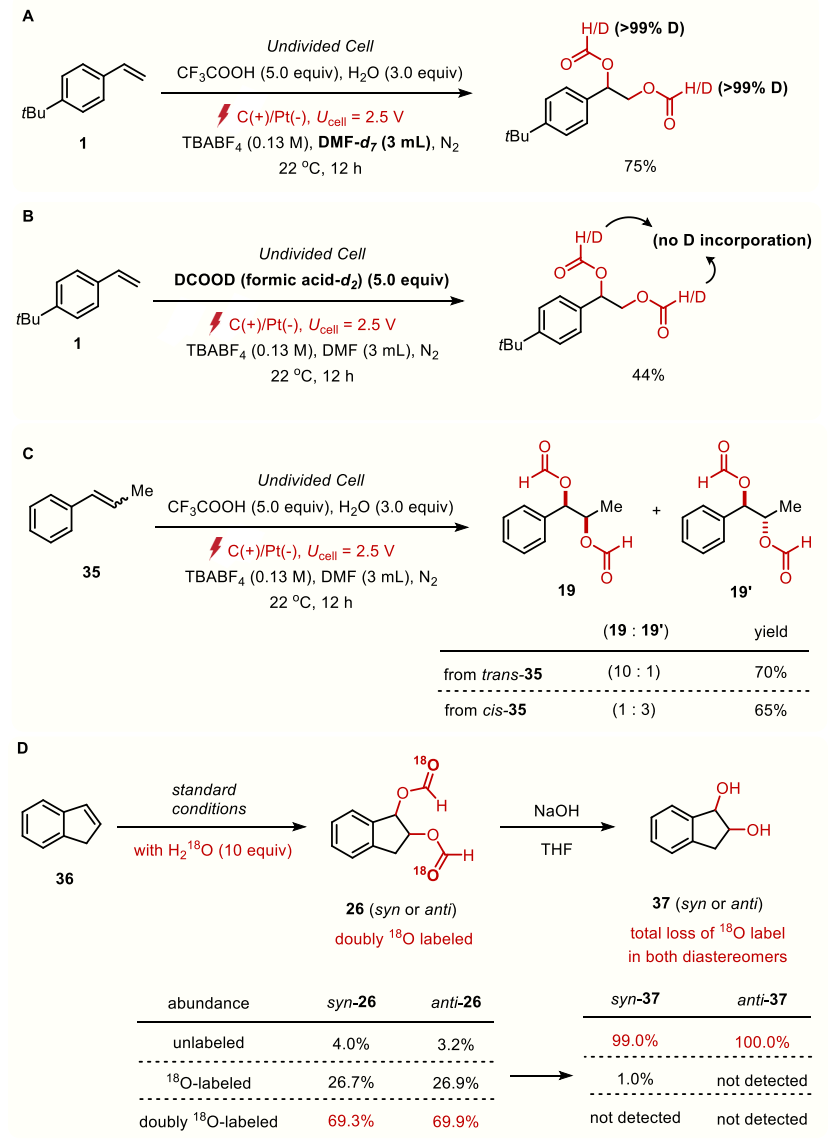

E

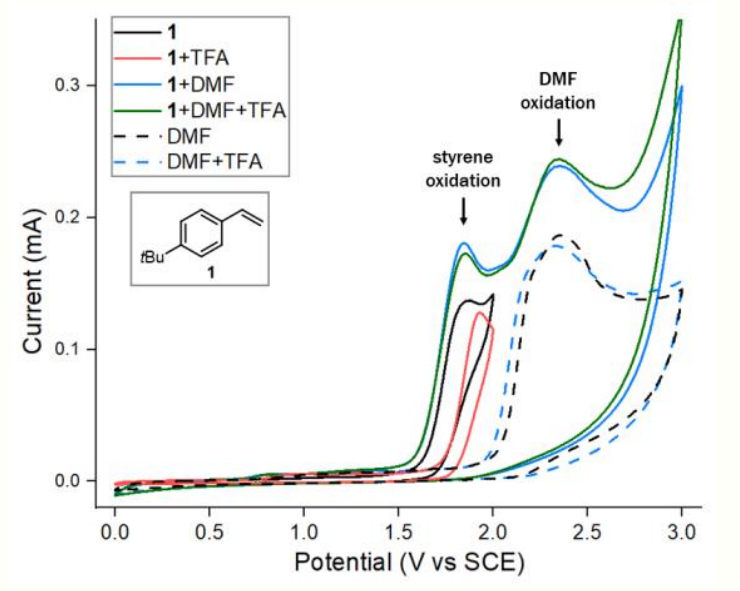

Figure 1 Mechanistic Investigations

To elucidate the origin of the oxygen atoms, we performed an isotopic labeling study with indene (36) as a substrate, us- ing $97 \% \mathrm{O}^{18}$ enriched water as an additive (Figure $\left.{ }_{1} \mathrm{D}\right)$. The relative amounts of doubly-labeled diformyloxylation products (>69.3\%) with singly-labeled $(<26.9 \%)$ and unlabeled $(<4 \%)$ products were determined for both diastereomers (syn- and anti-26), using high-resolution mass spectroscopy (HRMS). On the other hand, hydrolysis of the formyloxy groups resulted in significant removal of the oxygen 18-label, leading to the formation of unlabeled diol as the major product for both diastereomers (syn- and anti-37). These results suggest that both oxygens for the hydroxyl group originate from DMF during the reaction, not from water.

Cyclic voltammetry (CV) data showed that the oxidation of alkene $\mathbf{1}$ to the corresponding alkene radical cation results in a feature at around $\mathrm{E}_{\mathrm{p} / 2}=1.7 \mathrm{~V}$ (vs SCE; Figure $1 \mathrm{E}$, black line). The addition of TFA, DMF, or both did not cause significant anodic peak shift of this redox event in thermodynamically more feasible way, implying that the alkene substrate is directly oxidized on the carbon anode during the reaction. We also recognized the possibility of an oxidation of DMF prior to the alkene. However, such mechanism is proved to be difficult because of high oxidation potential of DMF $\left(\mathrm{E}_{\mathrm{p} / 2}=2.1 \mathrm{~V}\right.$, dashed black lines), even in the presence of TFA (dashed blue lines).

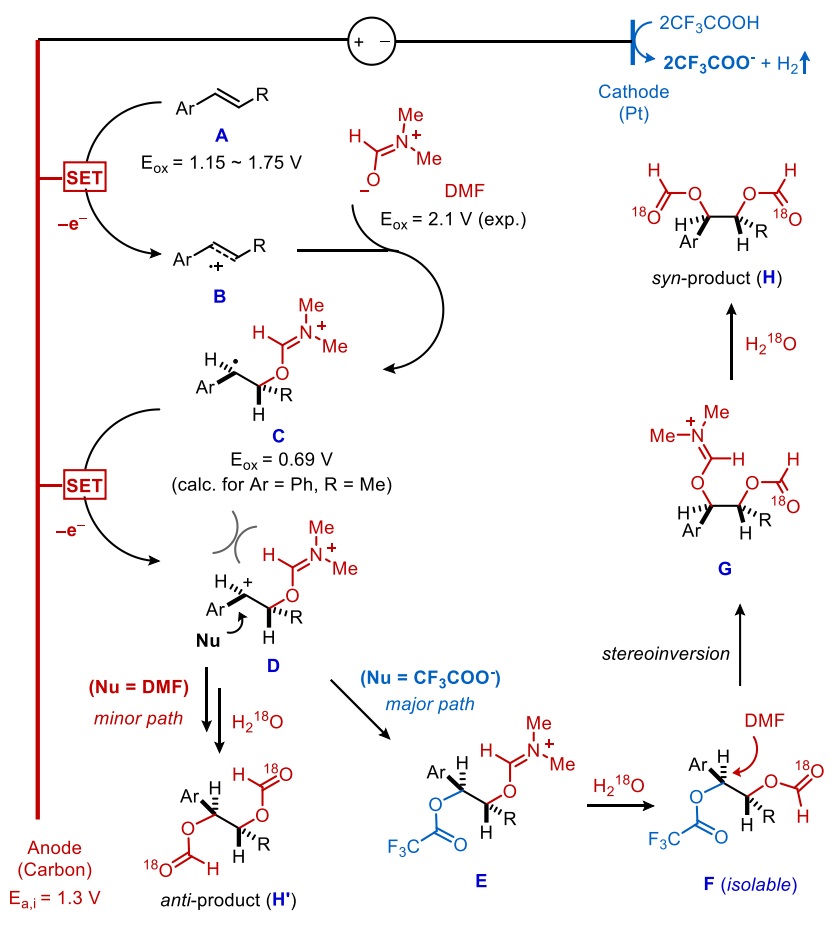

Figure 2 Mechanistic Rationale

On the basis of these experimental results and precedent literature, ${ }^{13}$ a mechanistic rationale is shown in Figure 2. First, electrochemical oxidation of the alkene substrate $\mathbf{A}$ generates the alkene radical cation $\mathbf{B}$ (the oxidation potentials $E_{o x}$ for the different vinylarenes tested range from $1.15 \mathrm{~V}$ to $1.75 \mathrm{~V}$ vs SCE). ${ }^{14}$ The low potential threshold for such electron transfer is reported to be $0.5 \mathrm{~V}$ lower than the thermodynamic potential of the substrate, ${ }^{15}$ which supports that our measured initial anodic potential $\left(\mathrm{E}_{\mathrm{a}, \mathrm{i}}=\right.$ 
1.3 V vs SCE) is above the onset potential of alkene oxidation. As an additional note, the anodic potential was maintained throughout the reaction, showing $1.22 \mathrm{~V}$ of the final anodic potential $\left(E_{a, f}\right)$. This result suggests that the desired reactivity can be achieved at the low potential threshold of the alkene oxidation. The nucleophilic trapping of B with DMF produces the carbon-centered radical $\mathbf{C}$, which is concurrently oxidized into the dication $\mathbf{D}$ on a carbon anode. Indeed, the second anodic oxidation is calculated to be thermodynamically more feasible than the first oxidation $\left(\mathrm{E}_{\mathrm{ox}}=0.69 \mathrm{~V}\right.$ vs SCE, when $\mathrm{Ar}=\mathrm{Ph}$ and $\mathrm{R}=\mathrm{Me}) .{ }^{16} \mathrm{~A}$ facile nucleophilic capture of sterically biased dication $\mathbf{D}$ by trifluroacetate ion would result in the predominant formation of an anti-dioxygenated intermediate $\mathbf{F}$, upon hydrolysis of iminium intermediate $\mathbf{E}$. A nucleophilic displacement of trifluoroacetate group ${ }^{17}$ from an isolable intermediate $\mathbf{F}$ by DMF eventually furnishes a syn-diformyloxylation product $\mathbf{H}$ followed by the second hydrolysis. It should be noted that the high diastereoselectivity observed in linear alkene substrates suggests that the formation of $\mathbf{E}$ occurs prior to the erosion of diastereocontrol caused by $\mathrm{C}-\mathrm{C}$ bond rotation. The reactivity trend upon the choice of acid observed in Table 1 is likely related to the final nucleophilic displacement step. Moreover, the role of TFA in affecting diastereoselectivity was also verified by a series of control experiments with internal alkene substrate, where TFA is replaced by other acids. ${ }^{18}$ We also recognized the possibility of a nucleophilic attack of $\mathbf{D}$ directly from DMF to give anti-diformyloxylation product $\left(\mathbf{H}^{\prime}\right)$. However, this pathway is considered to be less likely because trifluoroacetate is presumably a better nucleophile than DMF to capture dicationic intermediate $\mathbf{D}$ mainly due to its anionic character. This is also consistent to the predominant syn-diastereoselectivity of the current diformyloxylation protocol.

In conclusion, we devised an electrooxidative strategy that grants access to formyl-protected syn-1,2-diols from vinylarenes and DMF. This reaction is initiated by the electrochemical oxidation of the alkene substrates followed by the nucleophile attack of DMF. Mechanistic studies imply that trifluoroacetate ion is presumably engaged in the nucleophilic capture of the carbocation intermediate, which gives rise to high syn-diastereoselectivity. A simple deprotection of formyl protecting groups from the dioxygenated product was also presented, highlighting synthetic utility of this electrochemical method toward a variety of 1,2-diols. We anticipate this electrochemical synthetic approach promoted by trifluoroacetic acid will be broadly applicable in further development of nucleophilic olefin functionalization reactions.

\section{CONFLICTS OF INTERESTS}

There are no conflicts to declare.

\section{ACKNOWLEDGMENT}

This work was supported the National Research Foundation of Korea (NRF) grant funded by the Korea government (MSIT) [NRF-2020R1F1A1069242 (H. Kim)]. D. S. Chung acknowledges the National Research Foundation (NRF2019R1A6A3A13096586). This study made use of the NMR facility supported by Korea Basic Science Institute (National Research Facilities and Equipment Center) grant funded by the Ministry of Education (NRF-2020R1A6C101B194).

\section{AUTHOR INFORMATION}

\section{Corresponding Author}

* Sang-gi Lee - Department of Chemistry and Nano Science, Ewha Womans University, 0376o Seoul, Korea;

Email: sanggi@ewha.ac.kr

* Hyunwoo Kim - Department of Chemistry and Nano Science, Ewha Womans University, 0376o Seoul, Korea;

Email: khw7373@ewha.ac.kr

\section{Author Contributions}

§These authors contributed equally and are listed in an alphabetical order by last name.

\section{REFERENCES}

1 (a) J. I. Kroscwitz and M. Howe-Grant, Kirk-Othmer Encyclopedia of Chemical Technology, Wiley, New York, 1991; (b) K. Kulkaand and J. W. Dittrick, Cosmet. Perfum., 1975, 90, 90-95.

2 (a) R. B. Woodward and F. V. Brutcher, J. Am. Chem. Soc., 1958, 8o, 209-211; (b) C. Prévost, Compt. Rend., 1933, 196, 1129-1131; (c) C. Prévost and J. Wiemann, Compt. Rend., 1937, 204, 700-701; (d) B. Plesnicar and W. S. Trahanovsky. Oxidations in Organic Chemistry, Academic Press, New York, 1978; (e) L. Emmanuvel, T. M. A. Shaikh and A. Sudalai, Org. Lett., 2005, 7, 5071-5074; (f) S. Haubenreisser, T. H. Wöste, C. Martínez, K. Ishihara and K. Muñiz, Angew. Chem. Int. Ed., 2016, 55, 413-417.

3 (a) M. Schroeder, Chem. Rev., 1980, 8o, 187-213; (b) E. N. Jacobsen, I. Marko, W. S. Mungall, G. Schroeder and K. B. Sharpless, J. Am. Chem. Soc., 1988, 110, 1968-1970; (c) H. C. Kolb, M. S. VanNieuwenhze and K. B. Sharpless, Chem. Rev., 1994, 94, 2483-2547; (d) T. J. Donohoe, K. Blades, P. R. Moore, M. J. Waring, J. J. G. Winter, M. Helliwell, N. J. Newcombe and G. Stemp, J. Org. Chem., 2002, 67, 7946-7956; (e) I. T. Raheem, S. N. Goodman and E. N. Jacobsen, J. Am. Chem. Soc., 2004, 126, 706707; (f) T. J. Donohoe, R. M. Harris, S. Butterworth, J. N. Burrows, A. Cowley and J. S. Parker, J. Org. Chem., 2006, 71, 4481-4489.

4 (a) Y. Zhang and M. S. Sigman, J. Am. Chem. Soc., 2007, 129, 3076-3077; (b) Y. Li, D. Song and V. M. Dong, J. Am. Chem. Soc., 2008, 130, 2962-2964; (c) A. Wang, H. Jiang and H. Chen, J. Am. Chem. Soc., 2009, 131, 3846-3847; (d) C. P. Park, J. H. Lee, K. S. Yoo and K. W. Jung, Org. Lett., 2010, 12, 2450-2452; (e) Z. K. Wickens, P. E. Guzmán and R. H. Grubbs, Angew. Chem. Int. Ed., 2015, 54, 236-240; (f) J. Huang, L. Ouyang, J. Li, J. Zheng, W. Yan, W. Wu and H. Jiang, Org. Lett., 2018, 20, 5090-5093. (g) T. W.S. Chow, E. L.-M. Wong, Z. Guo, Y. Liu, J.-S. Huang and C.-M. Che, J. Am. Chem. Soc., 2010, 132, 13229-13239; (h) P. Saisaha, D. Pijper, R. P. van Summeren, R. Hoen, C. Smit, J. W. de Boer, R. Hage, P. L. Alsters, B. L. Feringa and W. R. Browne, Org. Biomol. Chem., 2010, 8, 44444450; (i) Y. B. Kang and L. H. Gade, J. Am. Chem. Soc., 
2011, 133, 3658-3667; (j) C. J. R. Bataille and T. J. Donohoe, Chem. Soc. Rev., 2011, 40, 114-128; (k) K. Chen, M. Costas, J. Kim, A. K. Tipton and L. Que, J. Am. Chem. Soc., 2002, 124, 3026-3035; (1) W.-P. Yip, W.-Y. Yu, N. Zhu and C.M. Che, J. Am. Chem. Soc., 2005, 127, 14239-14249; (m) J. Seayad, A. M. Seayad and C. L. L. Chai, Org. Lett., 2010, 12, 1412-1415.

5 (a) Y. Usui, K. Sato and M. Tanaka, Angew. Chem. Int. Ed., 2003, 42, 5623-5625 (b) J. C. Griffith, K. M. Jones, S. Picon, M. J. Rawling, B. M. Kariuki, M. Campbell and N. C. O. Tomkinson, J. Am. Chem. Soc., 2010, 132, 1440914411; (c) M. J. Rawling, N. C. O. Tomkinson, Org. Biomol. Chem., 2013, 11, 1434-1440. (d) W. Zhong, S. Liu, J. Yang, X. Meng and Z. Li, Org. Lett., 2012, 14, 3336-3339.

6 (a) B. C. Giglio, V. A. Schmidt and E. J. Alexanian, J. Am. Chem. Soc., 2011, 133, 13320-13322; (b) B. Yang and Z. Lu, Chem. Commun., 2017, 53, 12634-12637; (c) B.-Y. Wei, D.T. Xie, S.-Q. Lai, Y. Jiang, H. Fu, D. Wei and B. Han, Angew. Chem. Int. Ed., 2021, 6o, 3182-3188.

7 For representative articles on electrochemically driven organic synthesis, see: a) M. Yan, Y. Kawamata and P. S. Baran, Chem. Rev., 2017, 117, 13230-13319; (b) G. S. Sauer and S. Lin, ACS Catal., 2018, 8, 5175-5187; (c) P. Gandeepan, L. H. Finger, T. H. Meyer and L. Ackermann, Chem. Soc. Rev. 2020, 49, 4254-4272; (d) N. Sauermann, T. H. Meyer, Y. Qiu and L. Ackermann, ACS Catal., 2018, 8, 7086-7103; (e) C. Ma, P. Fang and T.-S. Mei, ACS Catal., 2018, 8, 7179-7189; (f) K. D. Moeller, Chem. Rev., 2018, 118, 4817-4833; (g) S. R. Waldvogel, S. Lips, M. Selt, B. Riehl and C. J. Kampf, Chem. Rev., 2018, 118, 67066765; (h) J. E. Nutting, M. Rafiee and S. S. Stahl, Chem. Rev., 2018, 118, 4834-4885; (i) S. Tang, Y. Liu and A. Lei, Chem, 2018, 4, 27-45; (j) P. Xiong and H.-C. Xu, Acc. Chem. Res., 2019, 52, 3339-3350; (k) J. Liu, L. Lu, D. Wood and S. Lin, ACS Cent. Sci., 2020, 6, 1317-1340; (1) R. D. Little, J. Org. Chem., 2020, 85, 13375-13390; (m) F. Wang and S. S. Stahl, Acc. Chem. Res., 2020, 53, 561-574; (n) S. Doobary, A. T. Sedikides, H. P. Caldora, D. L. Poole and A. J. J. Lennox, Angew. Chem. Int. Ed., 2020, 59, 1155-116o; (o) J.-i. Yoshida, A. Shimizu and R. Hayashi, Chem. Rev., 2018, 118, 4702-4730; (p) Y. Jiang, K. Xu and C.-C. Zeng, Chem. Rev., 2018, 118, 4485-4540; (q) H. Huang, Z. M. Strater and T. H. Lambert, J. Am. Chem. Soc., 2020, 142, 1698-1703; (r) L. Zhang, L. Liardet, J. Luo, D. Ren, M. Grätzel and X. Hu, Nat. Catal., 2019, 2, 366373. (s) Y. Ashikari, T. Nokami and J.-i. Yoshida, Org. Lett., 2012, 14, 938-941.

8 (a) C.-Y. Cai and H.-C. Xu, Nat. Commun., 2018, 9, 3551; (b) J. Wu, Y. Dou, R. Guillot, C. Kouklovsky and G.
Vincent, J. Am. Chem. Soc., 2019, 141, 2832-2837. (c) S. Zhang, L. Li, P. Wu, P. Gong, R. Liu, and K. Xu, Adv. Synth. Catal., 2019, 361, 485-489.

9 (a) M. M. Heravi, M. Ghavidel and L. Mohammadkhani, RSC Adv., 2018, 8, 27832-27862; (b) X. Sun, H. X. Ma, T. S. Mei, P. Fang and Y. Hu, Org. Lett., 2019, 21, 3167-3171.

10 B. M. Peterson, S. Lin and B. P. Fors, J. Am. Chem. Soc., 2018, 140, 2076-2079.

11 T. Cottineau, M. Richard-Plouet, J.-Y. Mevellec and L. Brohan, J. Phys. Chem. C, 2011, 115, 12269-12274.

12 (a) K. A. Margrey and D. A. Nicewicz, Acc. Chem. Res., 2016, 49, 1997-2006; (b) A. J. Perkowski and D. A. Nicewicz, J. Am. Chem. Soc., 2013, 135, 10334-10337; (c) C.-Y. Cai, X.-M. Shu and H.-C. Xu, Nat. Commun., 2019, 1o, 4953; (d) M. Ošeka, G. Laudadio, N. P. van Leest, M. Dyga, A. d. A. Bartolomeu, L. J. Gooßen, B. de Bruin, K. T. de Oliveira and T. Noël, Chem, 2021, 7, 255-266; (e) T. Patra, M. Das, C. G. Daniliuc and F. Glorius, Nat. Catal., 2021. 4, 54-61.

13 (a) A. J. J. Lennox, J. E. Nutting and S. S. Stahl, Chem. Sci., 2018, 9, 356-361; (b) C. Kingston, M. D. Palkowitz, Y. Takahira, J. C. Vantourout, B. K. Peters, Y. Kawamata and P. S. Baran, Acc. Chem. Res., 2020, 53, 72-83; (c) B. Dhakal, L. Bohe and D. Crich, J. Org. Chem., 2017, 82, 9263-9269.

14 H. G. Roth, N. A. Romero and D. A. Nicewicz, Synlett, 2016, 27, 714-723.

15 R. Francke and R. D. Little, Chem. Soc. Rev., 2014, 43, 2492-2521.

16 Oxidation potential of $\mathrm{C}$ ( when $\mathrm{Ar}=\mathrm{Ph}$ and $\mathrm{R}=\mathrm{Me}$ ) was calculated using quantum chemical simulations and referenced to the absolute oxidation potential of NHE ( $4.430 \mathrm{~V}$ ). See Supplementary Information (page S46) for details. For related references, see: (a) D. G. Truhlar, C. J. Cramer, A. Lewis and J. A. Bumpus, J. Chem. Educ. 2004, 81, 596; (b) H. Reiss and A. Heller, J. Phys. Chem., 1985, 89, 4207-4213.

17 (a) A. Abad, C. Agulló, A. C. Cuñat and I. Navarro, Synthesis, 2005, 2005, 3355-3361; (b) S. Gronert, A. E. Fagin, K. Okamoto, S. Mogali and L. M. Pratt, J. Am. Chem. Soc., 2004, 126, 12977-12983.

18 A set of control experiments was conducted where TFA is replaced by other acids using an internal alkene (trans-35) as a substrate. Both reactivity and syn-selectivity was decreased upon treatment of other acids, supporting that the mechanistic role of TFA is important in the final nucleophilic displacement step. See Supplementary Information (SI) page S12 for details. 